\title{
MACRO-COGNITIVE ANALYSIS OF DESIGN SKILLS FOR SUPPORTING ENGINEERING DESIGN EDUCATION
}

\author{
S. $L i *$, G. Gress \\ Schulich School of Engineering, University of Calgary \\ *Corresponding Author E-mail Address: simoli@ucalgary.ca
}

\begin{abstract}
Macro-cognition is a field of study that investigates how domain experts (e.g., firefighters and weather forecasters) make decisions and judgements for their work. This paper has adapted two models from macro-cognition to better understand design activities. The first one is the Data / Frame model, and it tells how a person's frame can influence the selection of information in the design process. The second one is the recognitionprimed decision (RPD) model, which shows how a design idea emerges with a person's recognition and mental simulation. Based on these models, we further suggest three intervention strategies (i.e., challenge, relate and demonstrate) to support the processes of sensemaking, recognition and mental simulation. We also suggest two evaluation aspects, i.e., relevance and fluency, to assess design activities.
\end{abstract}

Keywords: Macro-cognition: Sensemaking: Recognitionprimed decision: mental simulation: engineering design

\section{INTRODUCTION}

Teaching engineering design is not easy. We have approached it by teaching design methods (e.g., Dym and Little 2009; Ulrich and Eppinger 2015) but the results were not satisfactory. We recognize too that we cannot simply let students work on their design projects without any formative interventions because the effectiveness of learning can be questionable. In the end, we have come to some "middle" point that classifies and instructs typical design tasks, along with regulated progress reviews. While we think it is an improved direction, we want to search for a theoretical framework that can provide more insights of design education and improve our practice.

The search is based on the premise that design is a phenomenon of human thinking, and thus we start with the keyword cognition. In psychology, cognition is mainly referred to as information processing by humans (Smilek et al. 2010), and sample topics include perception, memory and language. These topics mainly cover some elementary processes that can be examined in a laboratory environment. To us, a lot of extensions are needed to bridge these cognitive processes to design activities because contextual background (vs lab) is important to understand human thinking in design activities. Thus, we do not take this field as an initial pursuit for now.

Another field is meta-cognition, which has been studied extensively in education (e.g., Flawell 1979; Schraw 1998). It has been classified into knowledge of cognition (awareness of own knowledge) and regulation of cognition (control and use of learning skills). Meta-cognition can help us to understand how designers review their own thinking to improve design practices. However, educational studies tend to examine the effectiveness of teaching and learning over some well-defined knowledge and skills in a classroom. In contrast, design activities are specific to the context of the design problem, which makes meta-cognition not easy to inform design education.

The last one is macro-cognition, which is the theme of this paper. The term macro-cognition is used to contrast the traditional cognitive research focusing on laboratorybased activities (namely, micro-cognition) (Klein et al. 2003). Researchers in this field aim to study how experts solve problems in a naturalistic environment. One early study that draws our attention is the firefighter case study, which shows that firefighters do not explicitly compare options for their decisions (Klein, 2008). It is aligned with our experience and observations that good design does not normally emerge by explicitly comparing many different concepts.

We further studied the processes that are classified in the field of macro-cognition. As a result, we have selected and elaborated two processes, sensemaking and recognition-primed decision (RPD), for design activities. These two macro-cognitive processes will be discussed in Sections 2 and 3, respectively. To support pedagogical development, we will suggest the intervention strategies and design assessments related to these processes in Section 4. Section 5 will provide some closing remarks.

\section{SENSEMAKING AND ENGINEERING DESIGN}

\subsection{Background and Model Description}

Sensemaking is a general concept that can cover multiple areas such as creativity, mental modeling and data 
fusion. From the macro-cognitive perspective, we adopt the definition from Klein et al. (2006a, page 71) as follows.

"Sensemaking is a motivated, continuous effort to understand connections (which can be among people, places, and events) in order to anticipate their trajectories and act effectively."

To elaborate the sensemaking mechanism, Klein et al. (2006b) have proposed a Data / Frame model, which is adapted in this paper. In brief, the Data / Frame model describes how data could change the frame of a sensemaker (i.e., a person who does the sensemaking). A sensemaker's frame can be considered a personal perspective or framework used to interpret the environment. Apparently, a frame is influenced by a person's knowledge and experience.

In contrast, data can be interpreted as signals from the environment, and it is external to and observable by the sense-maker. For example, data can be an event that motivates the sensemaking process and a piece of new knowledge that corrects some misconception. Upon the emergence of new data, a sense-maker may question their own frame, and there can be three possible actions.

* Preserve the frame. The sense-maker may question the quality of data that explains (away) the perceived inconsistency.

* Elaborate the frame. New data is used to extend and refine the existing frame.

* Reframe. New data makes the sense-maker think that the existing frame is not effective, and the sensemaker tries to compare other frames and seek a new one.

Figure 1 illustrates the three actions of the Data / Frame model. Consider the star-like icon (top right of the figure) as an analogy of a person's frame. This person tends to interpret the world (top left) using this frame. If the interpretation from the preserved frame does not work, the person may seek another frame by elaborating or reframing. Klein et al. (2006b) note that experts tend to be more confident to challenge (and then change) their own frames, while novices tend to hold on their frames with a less critical mind.

There is a difference between elaborating a frame and reframing. For example, consider a general inquiry about reducing energy consumption of a building. An expert in heating, ventilation, and air conditioning (HVAC) may focus on the mechanical systems of buildings. Then, elaborating a frame can be a study of HVAC efficiency and an exploration of new HVAC technologies. Yet, HVAC systems can only cover how energy is supplied (one frame) but they do not address the energy demand (another frame). For example, we may alter a zone's conditions to demand less energy from the HVAC systems without affecting occupants' comfort. Reframing in this case can involve comparing different frames (efficient energy supply vs. effective / economical zone control and conditioning).

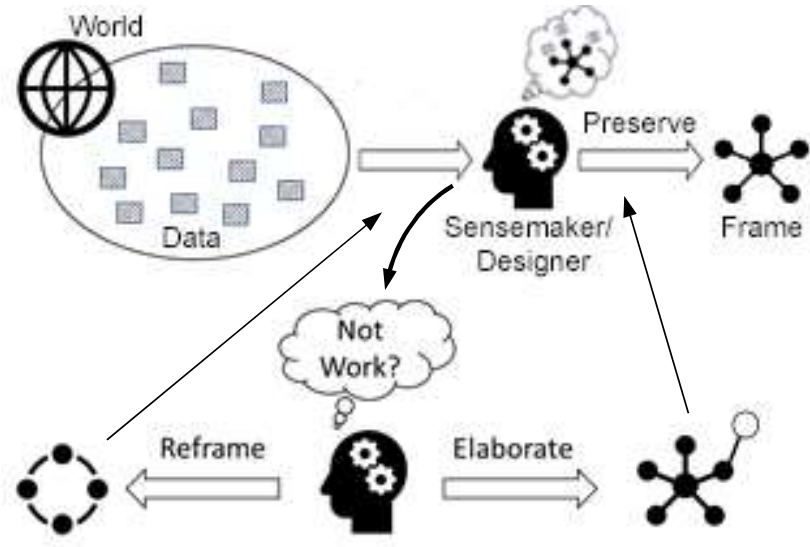

Fig. 1. Data / Frame model.

While data can influence a frame, the sense-maker does not receive data passively. On the contrary, a sensemaker's frame proactively manages the attention to external data. Using the above building energy example, if energy demand is the chosen frame, the sense-maker will focus on the occupants' activities, their comfort conditions and the zone environment. In other words, a frame often directs what data is deemed relevant at a time. Notably, frames can co-exist (or having a larger frame to coordinate two smaller frames). The message only highlights that a frame manages a sense-maker's attention to the relevant data. In turn, it constitutes the so-called data-frame symbiosis (Klein et al. 2006b, page 88) that a frame chooses data and data influences the frame.

The Data / Frame model has been used to explain some empirical findings (e.g., weather forecasters for situation awareness (Hoffman et al., 2006)). Some "less-intuitive" features of the Data / Frame model have helped to better understand how people do sensemaking, and these features are listed below.

* Our frame controls the way we acquire the data. It is typically suggested that a sense-maker should stay open and objective to external data. However, a sense-maker simply cannot treat all available data equally, and data relevant to their own frame tends to be managed first.

* We should not unintentionally avoid using our frame. It is a matter of effectiveness handling a lot of data that could be available in practice. Without using our frame, we cannot make effective connections for sensemaking. Staying open can imply doing nothing.

* We should keep challenging our frame. Experts are more conscious to question their own frames. That is, being adaptive is probably a better approach than staying open to the external data.

The next sub-sections will extend the Data / Frame model for two design activities: problem definition and design analysis. In particular, we believe that the frames of students have been strongly influenced by their school experience, and we want to examine how school-related frames may influence design work. 


\subsection{Sensemaking in Problem Definition}

By problem definition, we refer to the definition of a design problem in terms of requirements, specifications, objectives and constraints. Defining a design problem properly is often challenging. From the "problem-solution co-evolution" theory, designers may need to work on the design solutions first before they can define the design problems more clearly (Günther and Ehrlenspiel 1999).

Problem definition can be viewed as a sensemaking process. An initial design request can be viewed as data that motivates the designer to make sense of the design problem (e.g., why need a design, how the final design would look like). Departing from the design request, the designer will collect other data from their own frame (e.g., similar design objects learned before, problem solving experience). Speaking from students' experience, they are used to solving well-defined problems, which provide just enough clues from problem solving. For example, if four parametric values are required for problem solving, they may complain when the problem statement provides three values (do not know how to make assumptions) or five values (do not know how to filter the irrelevant data).

To further illustrate, consider a design request to redesign a wheelchair so that the user can move from a seating to a standing position easily and safely. Then, we may have three sensemaking processes as follows:

* Preserve the frame. Students check on the materials of previous courses (e.g., machine component design). They likely image a lifting device attached to a wheelchair to support the movement from seating to standing.

* Elaborate the frame. Beyond the course materials, students study alternative wheelchair designs and the designs of lifting devices that were not taught or known before.

- Reframe. Students ask why the user needs additional support moving from seating and standing. They will further examine the scenarios, in which seating-tostanding will likely occur. They may design some support structure that utilizes the user's strength (say, from their arms) for the motions (rather than using motors to provide the motions).

Notably, we do not imply that reframe is always better, and elaborating a frame can be sufficient for problem solving sometimes. One message here is that, without the sensemaking perspective, we may only be able to suggest: (1) listen carefully to the client's needs and (2) keep the mind open to the actual needs of the user.

On the other hand, while novices are bounded to their own frames, experienced designers tend to question their own frames more often (e.g., does the client really want a motorized lifting device?). We can encourage students to proactively interpret the design request from their own frame first. Then, seek feedback early from the client, and try to reflect on it by elaborating their own frame or reframing, which may require instructor guidance.

\subsection{Sensemaking in Design Analysis}

By design analysis, we refer to the analysis of the design objects using scientific and engineering principles. Design objects are not just physical artifacts, and they can be the results of the design process (e.g., a program, a chemical process). In the context of engineering design, it may be one key aspect to reflect what students have learned in scientific and technical courses.

In our view, design analysis can be a sensemaking process. In the teaching of scientific contents, we mostly focus on the questions of what and how. We may talk about why some scientific analysis is needed in practice (as a motivation for learning) but mostly not discussed critically. Consequently, when students approach design analysis, they mainly focus on what and how but pay less attention to the relevance of the analysis to the design problem. For example, in the design of a door's handle for energy harvesting, we do not expect the handle to experience extensive stress beyond the force from a human's arm. However, students may perform finite element analysis (FEA) to show how FEA can be used in this case (even though we know the handle's material is strong enough for normal operations without running FEA). To further illustrate, we may consider three sensemaking processes as follows.

- Preserve the frame. Starting from their own skillsets, students try to find which analyses can be performed in a design project. This process is mainly initiated by what students know but not necessarily by the nature of the design problem.

* Elaborate the frame. By examining the keywords of the design problem, students try to match the related analyses that could be done for the design project. This process tries to find a middle point between the knowledge of students and the need of the design problem.

* Reframe. Students recognize that energy harvesting is the technical bottleneck. Because it is not a familiar topic (in contrast to FEA) to them, they devote their efforts to research energy harvesting techniques and analyze possible design ideas.

Again, the essence of this sensemaking articulation is not that reframe is better. It is indeed quite natural for mechanical engineers to think mechanically or computer scientists to think computationally. One possible blind spot is the consideration of the relevance and necessity of a particular type of analysis for a design problem.

\section{RPD MODEL AND CONCEPTUAL DESIGN}

\subsection{Background}

Conceptual design is a critical stage of engineering design. A chosen idea in conceptual design often implies a strong commitment of efforts in a certain direction, which cannot be easily changed later. When people review any 
design mistakes, they can often track the issues back to conceptual design (e.g., overlook an important customer requirement). Traditionally, students are instructed to do conceptual design with two activities: concept generation and concept selection. Many design methods have been proposed to support these activities (e.g., morphological charts, TRIZ, decision matrix, etc.). The philosophy behind these activities is to promote creativity and avoid design mistakes by exploring many design ideas and selecting them carefully. We believe this philosophy was partly influenced by the rational decision theory, which prescribes the decision process for a rational being.

In contrast to the rational decision theory, the recognition-primed decision (RPD) model states that experts do not normally make decisions by comparing two (or more) options (Klein 1998, 2008). Instead, they first try to "recognize" the situation and compare it with their experience. Ideas can emerge in this context. Then, experts further "prime" these ideas via mental simulation until these ideas are good for the problem. This is similar to the "satisficing" concept by Simon (1996) that decision makers often do not have the resources for the "optimal" option and thus stay with a good enough choice. In the case study of firefighters, Klein (1998) has observed that the RPD model is more often adopted by experts (vs comparison of options). The RPD model has emerged in the area of "naturalistic decision making," which investigates how experts make decisions in a naturalistic (in contrast to laboratory) environment.

Then, why do we consider the RPD model in conceptual design? One major reason is that we find students do not necessarily get a better design idea by following the generate-then-select approach. More often, to fulfil the requirement of presenting multiple design concepts, they make up several options along with the "already-chosen" option as if they are making some rational decision. Also, one benefit of the RPD model is that it acknowledges the experience of the designers in the "recognizing" and "priming" activities. If we consider the RPD model in design education, we can examine how students use their experience in the design process and try to provide relevant instructions from there.

\subsection{Description of the RPD Model}

We describe the RPD model as a two-stage process (Klein 1998, pp. 24-28). The first stage seeks the recognition of a given situation. Such recognition takes four aspects: (1) goals to define the priorities, (2) cues to select relevant information, (3) expectancies to anticipate consequences and (4) actions to draft a possible solution. These four aspects work closely in a person's mind, and they do not necessarily follow one another in a prescribed order. For example, an emerging action triggers a search of some cues that reveal some expectancies of the action's consequences. In another case, expectancies may trigger the consideration of the original goals that stimulate another action. The outcome of the recognition stage is an action in response to the situation.

The next stage is the evaluation of a given action. After the recognition stage, this given action is considered tentatively plausible. Through mental simulation, this action will be evaluated by how it may work. The quality of mental simulation in this case depends on the experience of the designer (e.g., how capable the designer can predict the possible consequences and identify potential risks).

The two stages of the RPD model involve iterations respectively, as shown in Figure 2. In the recognition stage, when a designer faces an unfamiliar situation, he/she will search for more information and use the new information to familiarize the situation in a mind (a kind of a sensemaking process). In the evaluation stage, the designer may refine the action after some evaluation and evaluate the refined action again. If more changes are required, it can go back to the recognition stage. While this sub-section briefly overviews the RPD model, the next sub-sections will extend and contextualize the RPD model for conceptual design.

\subsection{Conceptual Generation through Recognition}

Conceptual design may start with a design problem statement, which can be well articulated or vaguely drafted. One situation that a designer should recognize is the clarity of the "given" design problem and the availability of the information. For example, the problem statement simply states, "Redesign a wheelchair so that the user can move from a seating to a standing position easily and safely." In the recognition stage, the designer should ask the questions for the clarity of the design problem such as:

* Goals: Why do we need a feature for supporting a seating-to-standing movement?

* Cues: How can we further the knowing of some keywords from the problem statement such as wheelchair and safety?

* Expectancies: How would the wheelchair user engage the new design feature?

* Actions: Can we use a hydraulic jack for the lifting motion?

Beyond the clarity aspect, the designer may not be familiar with the design problem, and it should initiate the iterative loop of recognition. This will involve an active search for new information, and further questions are identified such as:

* Goals: What can the performance metrics be to measure the quality of the final design?

* Cues: Are there any existing designs to support similar functions?

* Expectancies: Will the new design feature make the wheelchair too heavy for the user?

* Actions: Can we 3D-print the whole design?

While the above questions look natural for a designer to tackle a design problem, the methodical design approach mainly asks designers to complete the problem definition 
first before researching and proposing solutions. This implies a kind of waterfall process, where one step needs to be completed satisfactorily before moving to the next step. In contrast, the recognition stage of the RPD model shares the notion of the problem-solution co-evolution (Ball and Christensen 2019) that the designer takes some design ideas to better understand the design problem.

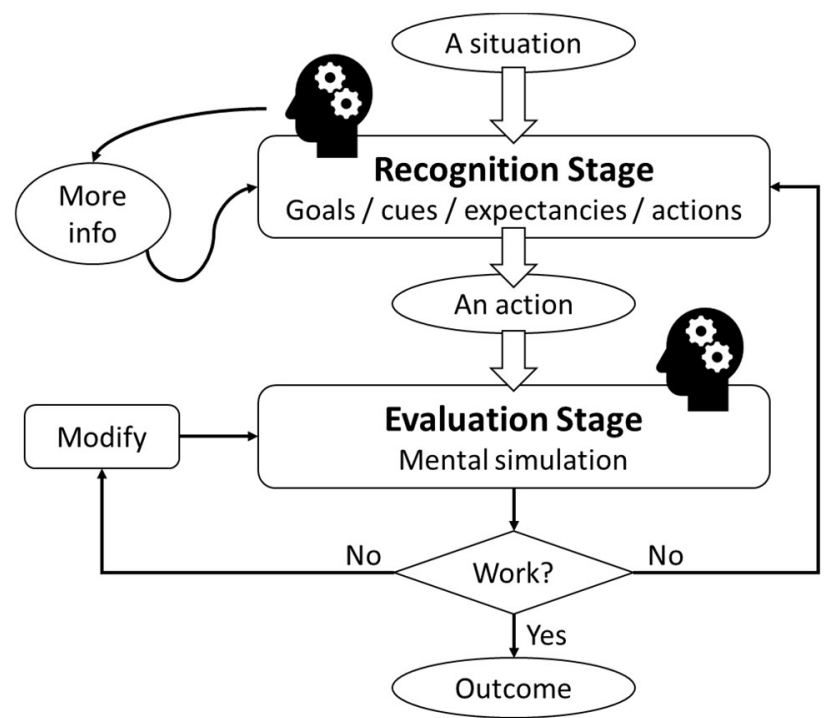

Fig. 2. Recognition-primed decision (RPD) model.

Notably, the RPD model does not ask for multiple design solutions from a designer. An action (or proposed design concept) can proceed to the evaluation stage as long as it makes sense to the designer. Of course, it does not imply that any proposed design concept will always be good in this case (it somewhat depends on the designer's experience to pass the design concept). On the other side, we argue that pushing for multiple design concepts would not be effective for a better design. Instead, following the RPD model, we can challenge the recognition deficiencies of a proposed design concept such as:

* Goals: How will you demonstrate the success of the proposed design concept?

* Cues: How do you compare the proposed design with the design of a height-adjustable desk?

* Expectancies: How heavy do you expect the proposed design to be approximately?

- Actions: Have you considered a design idea that does not require external power?

In other words, the design strategy in this case is to challenge and refine the proposed design concept. The benefit of this strategy is to base the discussion on the original design experience of the students, rather than inquiring the use of some methods that students may not be familiar with.

One challenge to this recognition process in conceptual design is the issue of design fixation. That is, a designer can be so biased to the initial idea, and he/she fails to consider other better alternatives. The design fixation effect has been studied in various ways (Jansson and Smith 1991; Crilly 2015). Yet, a deeper question is whether we can avoid design fixation completely. Design activities often engage a designer's experience, and we cannot do design with a clean / unbiased mind. Then, a more relevant issue is how to engage proper information and experience for good design practice. With the above recognition aspect, design fixation can be addressed by pointing out the deficiencies or overlooked aspects of the proposed design concept.

In a team situation, a complex design may require all team members to look into different aspects of the design problem. Then, proposing one design concept at the end is acceptable. For a simpler design in contrast, each team member can develop their own design concept and at their own speed, and the comparison of multiple design options is workable in this case. Here, we are not rejecting the generate-then-select approach in conceptual design entirely. We mainly want to illustrate that the RPD model can be a good reference for students to work on their design.

\subsection{Mental Models and Simulation in Conceptual Design}

Mental models can be generally defined as the mental representation a person has to understand the environment (Doyle and Ford 1988, Schraagen et al. 2017, page 64). The inventory and operations of mental models highly depend on a person's knowledge and experience. In the engineering design context, we categorize four types of mental models that can be relevant. The previous example of the seating-to-standing wheelchair design is used for the illustration.

(1) Mental model of design objects. It supports designers to understand how some objects work and operate. Relevant insights can help them replicate and adapt existing designs for solving a design problem. Examples include the typical geometry and operations of wheelchairs. It can also include the knowledge about how the patients use the wheelchairs.

(2) Mental model of design realization. Design realization is referred to the process to implement the design idea. It supports designers to assess the feasibility of a design solution under certain considerations. Examples include the prototyping techniques for various wheelchair components (e.g., how long it takes to make one part in 3D printing vs $\mathrm{CNC}$ machining, what kind of make-quality we may expect).

(3) Mental model of scientific analysis. It is referred to the scientific knowledge of designers, including the use of analysis tools (e.g., FEA, dimensional analysis) to know the properties of a design solution. It supports designers to choose the right tools and investigate relevant information. Examples include the stress, kinematic and usability analyses of a wheelchair. Besides the technical contents, it can also include the experience with these analyses. For 
example, the designer knows the typical stress level of some standard wheelchair component, which is not changed too much in the new design.

(4) Mental model of project management. Some experience with the execution of design projects can help designers understand typical demands and efforts required for different design tasks. It supports designers to understand the risks of a design project at different stages and situations. Examples include the timeline of design projects similar in scope to the wheelchair design, as well as durations and risks associated with some design tasks.

In the context of the RPD model, mental models and simulation can be used to evaluate an action from the recognition stage. To illustrate, we suppose one action for a design idea and one action for a schedule item. Using the wheelchair example, we discuss how mental simulation can be used to evaluate these actions below.

Regarding an action for a design idea, a scissor mechanism powered by an electrical motor is proposed to support the seating-to-standing function of the wheelchair chair. Mental simulation will examine how the scissor mechanism can be implemented to a wheelchair (design object) and may interfere with other moving parts (scientific analysis - kinematics). Concerning design realization, it will examine the resources required to support the proposed motor (e.g., the capacity and cost of a motor / battery). Here, mental simulation tries to examine a given design idea to a certain depth from different aspects. If the design idea cannot pass some evaluation criteria by mental simulation, the designer will try to refine it further or explore others. One essence of the RPD model is that it does not compare multiple options in parallel because one action already requires significant cognitive capacity, even for experienced designers, who may just consider it in more detail or more thoroughly.

Regarding an action for a schedule item, suppose that the overall project schedule proposes one week to test the wheelchair prototype at the end. Mental simulation will examine how the time of a week can be used for the design testing activities (project management). This mental simulation will require some knowledge about the operations of the final design (design object) and proper testing / experimental procedure (scientific analysis). If it is recognized that the one-week schedule is not sufficient for design testing, the project schedule may need to be revised, e.g., pushing back the date to finalize the design idea. This proposed schedule revision will then lead to another round of mental simulation. As discussed, mental simulation is not a prescribed, sequential process. It engages different mental models to work interdependently to evaluate the quality of a given action.

\section{PEDAGOGICAL SUGGESTIONS}

This paper has discussed three macro-cognitive processes for design activities: (1) sensemaking, (2) recognition and (3) mental simulation. As these processes are not entirely knowledge or information based, the pedagogical approach is not too much about "teaching" new contents. We want to focus on the facilitation of these processes for better design practices.

\subsection{Intervention Strategies}

Interventions can be generally interpreted as the instructional approach to a course. In our observations, students do not effectively improve their macro-cognitive processes just by asking them to work on a design project. In the role of instructors, we want to intervene in some student work so that they can reflect on their macrocognitive processes and eventually improve design quality and practices. We have thought of three intervention strategies for this purpose.

* Challenge. A cognitive process is somewhat related to a person's belief and habit, and thus students will not likely change their way of thinking until facing some "crisis." The intent of the "challenge" strategy is to prompt some deficiencies of the design thinking so that students are motivated to re-examine their current work.

* Relate. When students receive a "challenge", they may need some "hints" to relate relevant information (or resources) and move to the next steps. The intent of the "relate" strategy is not entirely about giving instructions. Instead, it is intended to help students relate to information (or resources) they are unaware of and see the design problem in a different angle.

* Demonstrate. In design, we think that it is not important whether the students listen to our suggestions or not. What is more important is to let them experience the reasoning process that can help them do better jobs later. So the intent of the "demonstrate" strategy is to show and explain our reasoning if some design suggestion is adopted.

Even they do not adopt the suggestion, the demonstration can help them review the project after its completion.

Table 1 shows some samples that employ these three strategies for the macro-cognitive processes in design.

The intervention strategies discussed here do not cover the instructional implementation (which involves other considerations). As a remark, we consider that the lecturebased approach will not be effective in this case because these strategies are not about content delivery. Instead, we organize progress reviews with individual teams at some important design stages (e.g., proposal of a design idea). During the review meetings, we first ask the team to briefly present some project contents. Based on our observations, we intervene with the questions of "challenge" and "relate". To support the team's next steps, we "demonstrate" some reasoning and possible outcomes if some actions are taken. 
In the traditional school environment, an instructor normally takes the power or authoritative position, while students are followers. In design education, we want to empower students in their execution of the design projects. That is, they should have more control about what they want to learn and experience from the design projects. We believe, without such empowerment, students would learn passively, and their macro-cognitive processes would not be engaged for improvement. With this intent, the three strategies of interventions are not exactly asking students to follow some instructions. Instead, the empowerment starts with some challenges that students may not recognize initially. Then, we provide them (more relevant) information and resources. In the design project, students remain in the driver seat, and they are responsible for their choices in the learning / design process. Even if the design results are not good at the end, the ownership of the design process can motivate students to recognize their own work and aim for improved work in the future.

Table 1: Samples of intervention strategies for macrocognitive processes.

\begin{tabular}{|c|c|c|c|}
\hline & Challenge & Relate & Demonstrate \\
\hline 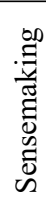 & $\begin{array}{l}\text { Question the } \\
\text { relevance of the } \\
\text { preserved frame } \\
\text { to the design } \\
\text { problem. }\end{array}$ & $\begin{array}{l}\text { Suggest and } \\
\text { explain a better } \\
\text { frame for the } \\
\text { design problem. }\end{array}$ & $\begin{array}{l}\text { Simulate } \\
\text { (verbally) the } \\
\text { possible path of } \\
\text { the design } \\
\text { process from a } \\
\text { different frame. }\end{array}$ \\
\hline 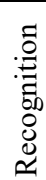 & $\begin{array}{l}\text { Examine the } \\
\text { relevance of the } \\
\text { background } \\
\text { research for the } \\
\text { design problem. }\end{array}$ & $\begin{array}{l}\text { Present some } \\
\text { design examples } \\
\text { that may support } \\
\text { the emergence of } \\
\text { a design idea. }\end{array}$ & $\begin{array}{l}\text { Explain my own } \\
\text { reasoning if I am } \\
\text { asked to propose } \\
\text { a design idea. }\end{array}$ \\
\hline 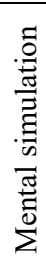 & $\begin{array}{l}\text { Criticize the } \\
\text { perceived results } \\
\text { from students' } \\
\text { mental } \\
\text { simulations. }\end{array}$ & $\begin{array}{l}\text { Highlight tools } \\
\text { that support } \\
\text { mental simul. at } \\
\text { some design } \\
\text { stages (e.g., } \\
\text { sketches, 3D } \\
\text { printing). }\end{array}$ & $\begin{array}{l}\text { Run the timeline } \\
\text { of the project } \\
\text { with more details } \\
\text { of design } \\
\text { activities. }\end{array}$ \\
\hline
\end{tabular}

\subsection{Assessment Strategies}

Unlike some technical courses mainly involving right vs wrong answers, design assessments often involve a judgment of good vs poor, which is not an easy task. Instructors may take the outcome-based principle that the assessment of a design project depends on the quality of the final design (e.g., how well it solves the design problem). While it makes sense in an industrial setting, it cannot effectively assess how well a group of students learns in a design project (which should be one educational aim). For example, it may be unfair to a student team who learns a lot in a challenging project but the prototype fails unexpectedly at the end.

Another assessment approach is process-based. That is, it assesses how well the design team executes some design steps or processes (e.g., the use of decision matrix for concept selection). While this process-based approach can be direct to assess design activities, the assessments may have no relation to the quality of the final design. For example, the design team can (just) focus on the grading rubrics and the required design steps closely without considering the design problem carefully. As a result, this team can receive a good grade, but their design may not solve the problem reasonably and practically.

From the macro-cognitive aspect, we suggest design assessments in two aspects: relevance and fluency. Relevance is about how useful the background research, scientific analysis and choice of other information are for the design problem. In the Data / Frame model of sensemaking, a good designer should be comfortable to reflect on their own frame to the context of the design problem. Then, we can check on the relevance of the presented information (e.g., background research and performance metrics) for design assessments. Irrelevant information often indicates that the students cannot (or do not want to) elaborate or reframe their original frame. Consider Section 2.2 about problem definition, if the students' frame is so biased to the lifting mechanism from a machine design course, their background research will review various lifting mechanisms. In contrast, they may not study the biomechanical analysis of humans from seating to standing, which should be more relevant. Section 2.3 has also discussed the sensemaking of design analysis, which implies some deficiencies if the students attempt to preserve their own frames in design.

Fluency is referred to the reasoning process for the design idea, the scientific analysis and the verification. In the RPD model, a design idea should have been evaluated by mental simulation. Then, how clear students can describe the design idea can be a good checkpoint. Poor description often implies that students have not thought about the design idea carefully. Also, when a type of scientific analysis is chosen, we can ask how the analysis results can be used to inform some design details. This requires students to mentally simulate the use of the scientific analysis in the design context, and it is a skill more than just knowing the scientific principles. When we demand design verification, students are required to mentally test the design idea. It can go beyond the basic functions to the examination of the design idea running in different situations.

In literature, design assessments have been framed as the comparison of responses from novice vs expert (Atman et al. 2007; Björklund 2013). This paper adapts this idea. Table 2 suggests some rubrics questions for design assessments, along with some possible responses from weak vs strong students for the wheelchair design.

\section{CLOSING REMARKS}

This paper adapts two models from macro-cognition to describe design activities: Data / Frame model and 
Recognition-Primed Design (RPD) model. The Data / Frame model indicates the importance of a person's frame to select and make sense of data. The RPD model reveals how the recognition process and mental simulation support a designer to develop a design idea. Based on these two models, we suggest three intervention strategies (i.e., challenge, relate and demonstrate) and two assessment aspects (i.e., relevance and fluency) to support the training of sensemaking, recognition and mental simulation for the improvement of design skills.

This work is an initial exploration of a theoretical framework to understand how students design. The next step is to design some empirical studies to examine and modify these models to better support design education.

Table 2: Sample rubrics questions for design assessments.

\begin{tabular}{|c|c|c|}
\hline Question & Weak & Strong \\
\hline $\begin{array}{l}\text { Relevance: } \\
\text { How well the } \\
\text { team explores } \\
\text { useful info for } \\
\text { design? }\end{array}$ & $\begin{array}{l}\text { Check the yield } \\
\text { strength of a } \\
\text { material to support } \\
\text { a person }\end{array}$ & $\begin{array}{l}\text { Learn the } \\
\text { leveraging point for } \\
\text { user from seat to } \\
\text { stand }\end{array}$ \\
\hline $\begin{array}{l}\text { Relevance: } \\
\text { How indicative } \\
\text { of the } \\
\text { performance } \\
\text { metrics set by } \\
\text { the team? }\end{array}$ & $\begin{array}{l}\text { Lifting force } \\
\text { (higher } \rightarrow \text { better) }\end{array}$ & $\begin{array}{l}\text { Time required for a } \\
\text { patient to complete } \\
\text { a prescribed action } \\
\text { (shorter } \rightarrow \text { better) }\end{array}$ \\
\hline $\begin{array}{l}\text { Relevance: } \\
\text { How suitable is } \\
\text { the scientific } \\
\text { analysis chosen } \\
\text { for the design } \\
\text { study? }\end{array}$ & $\begin{array}{l}\text { Computational fluid } \\
\text { dynamics (CFD) to } \\
\text { examine the added } \\
\text { drag from the } \\
\text { design }\end{array}$ & $\begin{array}{l}\text { Biomechanical } \\
\text { analysis of user } \\
\text { from seat to stand }\end{array}$ \\
\hline $\begin{array}{l}\text { Fluency: } \\
\text { How clear the } \\
\text { team can } \\
\text { describe the } \\
\text { operations of the } \\
\text { final design? }\end{array}$ & $\begin{array}{l}\text { Only describe how } \\
\text { an electrical motor } \\
\text { drives the scissor } \\
\text { mechanism to lift a } \\
\text { platform. }\end{array}$ & $\begin{array}{l}\text { Describe how the } \\
\text { design supports a } \\
\text { patient's move in } \\
\text { three stages. }\end{array}$ \\
\hline $\begin{array}{l}\text { Fluency: } \\
\text { How properly } \\
\text { the scientific } \\
\text { analysis is } \\
\text { integrated for the } \\
\text { design problem? }\end{array}$ & $\begin{array}{l}\text { CFD results are not } \\
\text { used to inform any } \\
\text { design details. }\end{array}$ & $\begin{array}{l}\text { Biomechanical } \\
\text { analysis reveals that } \\
\text { less external } \\
\text { support is required } \\
\text { when approaching a } \\
\text { standing position. } \\
\text { Design details focus } \\
\text { on the support for } \\
\text { leaving the seating } \\
\text { area. }\end{array}$ \\
\hline $\begin{array}{l}\text { Fluency: } \\
\text { How thorough } \\
\text { the team plans to } \\
\text { verify the design } \\
\text { idea. }\end{array}$ & $\begin{array}{l}\text { Indicate the design } \\
\text { can lift a weight of } \\
100 \mathrm{~kg} \text {. }\end{array}$ & $\begin{array}{l}\text { Plan a series of } \\
\text { testing for users } \\
\text { with different } \\
\text { physical needs. }\end{array}$ \\
\hline
\end{tabular}

\section{Acknowledgements}

This research is supported by the NSERC Chair in Design Engineering.

\section{References}

[1] Atman, C.J., R.S. Adams, M.E. Cardellla, J. Turns, S. Mosborg and J. Saleem, "Engineering design processes : A comparison of students and expert practitioners," Journal of Engineering Education, vol. 94, no. 4, pp. 359-379, 2007.

[2] Ball, L.J. and B.T. Christensen, "Advancing an understanding of design cognition and design metacognition: Progress and prospects," Design Studies, vol. 65, pp. 35-59, 2019.

[3] Björklund, T.A., "Initial mental representations of design problems: Differences between experts and novices," Design Studies, vol. 34, no. 2, pp. 135-160, 2013.

[4] Crilly, N., "Fixation and creativity in concept development: The attitudes and practices of expert designers," Design Studies, vol. 38, pp. 54-91, 2015.

[5] Doyle, J.K. and D.N. Ford, "Mental models concepts for system dynamics research," System Dynamics Review, vol. 14, no. 1, pp 3-29, 1998.

[6] Dym, C.L. and P. Little, Engineering Design: A ProjectBased Introduction. Hoboken, NJ: John Wiley \& Sons, 2009 (3rd ed.).

[7] Flavell, J.H., "Metacognition and cognitive monitoring: A new area of cognitive-developmental inquiry," American Psychologist, vol. 34, no. 10 pp. 906-911, 1979.

[8] Günther, J. and K. Ehrlenspiel, "Comparing designers from practice and designers with systematic design education," Design Studies, vol. 20, no. 5, pp. 439-451, 1999.

[9] Hoffman, R.R., G. Trafton and P. Roebber, Minding the Weather: How Expert Forecasters Think. Cambridge, MA: MIT Press, 2006.

[10] Jansson, D.G. and S.M. Smith, "Design fixation," Design Studies, vol. 12, no. 1, pp. 3-11, 1991.

[11] Klein, G., Sources of Power: How People Make Decisions. Cambridge, MA: MIT Press, 1998 (20 ${ }^{\text {th }}$ Anniversary Ed.).

[12] Klein, G., "Naturalistic decision making," Human Factors, vol. 50, no. 3, pp. 456-460, 2008.

[13] Klein, G., B. Moon and R.R. Hoffman, "Making sense of sensemaking 1: Alternative perspectives," IEEE Intelligent Systems, vol. 21, no. 4, pp. 70-73, 2006a.

[14] Klein, G., B. Moon and R.R. Hoffman, "Making sense of sensemaking 2: A macrocognitive model," IEEE Intelligent Systems, vol. 21, no. 5, pp. 88-92, 2006b.

[15] Klein, G., K.G. Ross, B. Moon, D.E. Klein, R.R. Hoffman and E. Hollnagel, "Macrocognition," IEEE Intelligent Systems, vol. 18, no. 3, pp. 81-85, 2003.

[16] Schraagen, J., L. Militello, T. Ormerod and R. Lipshitz (editors), Naturalistic Decision Making and Macrocognition. Hampshire, England: Ashgate Publishing Limited, 2017.

[17] Schraw, G., "Promoting general metacognitive awareness," Instructional Science, vol. 26, pp. 113-125, 1998.

[18] Simon, H., The Sciences of the Artificial. Cambridge, MA: MIT Press, 1996 (3rd ed.).

[19] Smilek, D., S. Sinnett and A. Kingstone, Cognition, Ontario, Canada: Oxford University Press, 2013 (5 ${ }^{\text {th }}$ ed.).

[20] Ulrich, K.T. and S.D. Eppinger, Product Design and Development. New York, NY: McGraw-Hill Education, 2015 (6th ed.). 